\title{
Letter to the Editor in Reference to the Article Entitled "Effects of Carbonated Liquids on Oropharyngeal Swallowing Measures in People with Neurogenic Dysphagia"
}

\author{
Alireza Salarinejad ${ }^{1} \cdot$ Hamid Reza Farpour $^{2} \cdot$ Sima Farpour $^{1}$ (D) \\ Received: 9 November 2019 / Accepted: 12 May 2020 / Published online: 19 May 2020 \\ ○) Springer Science+Business Media, LLC, part of Springer Nature 2020
}

\begin{abstract}
This letter is written according to stoichiometric calculation doubt about the article entitled "effects of carbonated liquids on oropharyngeal swallowing measures in people with neurogenic dysphagia" by Sdravou et al.
\end{abstract}

Keywords Deglutition $\cdot$ Dysphagia $\cdot$ Oropharyngeal swallowing $\cdot$ Carbonated beverage $\cdot$ Liquid $\cdot$ Stoichiometry

\section{To the editor,}

We are writing to you in reference to the article entitled "Effects of carbonated liquids on oropharyngeal swallowing measures in people with neurogenic dysphagia" by Sdravou et al. [1]. The article is well written and interesting. However, there is a doubt in its methodology which should be considered.

According to the methodology of the article, $1.3 \mathrm{mg}$ citric acid with $4 \mathrm{~g}$ sodium bicarbonate is used to produce carbonated thin liquid; while according to the stoichiometry rules of the reaction $\mathrm{C}_{6} \mathrm{H}_{8} \mathrm{O}_{7}+3 \mathrm{NaHCO}_{3}=3 \mathrm{H}_{2} \mathrm{O}+3 \mathrm{CO}_{2}+\mathrm{Na}_{3} \mathrm{C}_{6} \mathrm{H}_{5} \mathrm{O}_{7}$ [2], each mole of citric acid will react with 3 mol of sodium bicarbonate in which the molecular weight of $1 \mathrm{~mol}$ of citric acid anhydrous is $192.12 \mathrm{~g} \mathrm{[3]}$ and the molecular weight of each 3 mol of sodium bicarbonate is $252 \mathrm{~g}$ [4].

Therefore, $1.7 \mathrm{~g}$ sodium bicarbonate should be used to neutralize $1.3 \mathrm{~g}$ citric acid. But in the article, $4 \mathrm{~g}$ sodium

Sima Farpour

sima.farpour@gmail.com

Alireza Salarinejad

irpoment@gmail.com

Hamid Reza Farpour

farporh@gmail.com

1 Neuroscience Research Center, Institute of Neuropharmacology, Kerman University of Medical Sciences, Kerman, Iran

2 Shiraz Geriatric Research Center, Bone and Joint Diseases Research Center, Shiraz University of Medical Sciences, Shiraz, Iran bicarbonate was used; so $2.3 \mathrm{~g}$ sodium bicarbonate will leave excess in the reaction medium. So according to this phenomenon, the results of the experiment may be affected. Hence, we recommend evaluating the possible effect of this excess amount of sodium bicarbonate in the results of the study.

\section{References}

1. Sdravou K, Walshe M, Dagdilelis L (2012) Effects of carbonated liquids on oropharyngeal swallowing measures in people with neurogenic dysphagia. Dysphagia 27(2):240-250. https://doi. org/10.1007/s00455-011-9359-8

2. Patel SG, Siddaiah M (2018) Formulation and evaluation of effervescent tablets: a review. J Drug Deliv Therap 8(6):296-303. https ://doi.org/10.22270/jddt.v8i6.2021

3. National Center for Biotechnology Information. PubChem Database. Citric acid, CID=311, https://pubchem.ncbi.nlm.nih.gov/ compound/Citric-acid. Accessed 23 Oct 2019

4. National Center for Biotechnology Information. PubChem Database. Sodium bicarbonate, CID=516892, https://pubchem.ncbi. nlm.nih.gov/compound/Sodium-bicarbonate. Accessed 23 Oct 2019

Publisher's Note Springer Nature remains neutral with regard to jurisdictional claims in published maps and institutional affiliations.

Alireza Salarinejad Pharm.D, PhD

Hamid Reza Farpour MD

Sima Farpour $\mathrm{MSc}, \mathrm{PhD}$ 